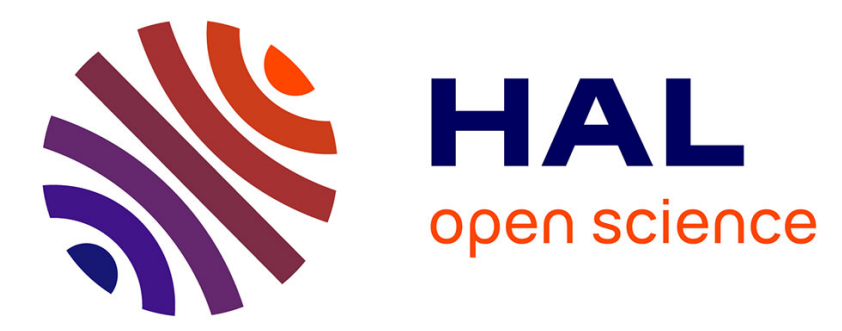

\title{
Cyber-Physical Waste Identification and Elimination Strategies in the Digital Lean Manufacturing World
}

David Romero, Paolo Gaiardelli, Matthias Thürer, Daryl Powell, Thorsten Wuest

\section{- To cite this version:}

David Romero, Paolo Gaiardelli, Matthias Thürer, Daryl Powell, Thorsten Wuest. Cyber-Physical Waste Identification and Elimination Strategies in the Digital Lean Manufacturing World. IFIP International Conference on Advances in Production Management Systems (APMS), Sep 2019, Austin, TX, United States. pp.37-45, 10.1007/978-3-030-30000-5_5 . hal-02419262

\section{HAL Id: hal-02419262 \\ https://hal.inria.fr/hal-02419262}

Submitted on 19 Dec 2019

HAL is a multi-disciplinary open access archive for the deposit and dissemination of scientific research documents, whether they are published or not. The documents may come from teaching and research institutions in France or abroad, or from public or private research centers.
L'archive ouverte pluridisciplinaire HAL, est destinée au dépôt et à la diffusion de documents scientifiques de niveau recherche, publiés ou non, émanant des établissements d'enseignement et de recherche français ou étrangers, des laboratoires publics ou privés.

\section{(c)(1)}

Distributed under a Creative Commons Attribution| 4.0 International License 


\title{
Cyber-Physical Waste Identification and Elimination Strategies in the Digital Lean Manufacturing World
}

\author{
David Romero $^{1}$, Paolo Gaiardelli ${ }^{2}$, Matthias Thürer ${ }^{3}$, Daryl Powell ${ }^{4}$, Thorsten Wuest ${ }^{5}$ \\ ${ }^{1}$ Tecnológico de Monterrey, Mexico \\ david.romero.diaz@gmail.com \\ ${ }^{2}$ University of Bergamo, Italy \\ paolo.gaiardelli@unibg.it \\ ${ }^{3}$ Jinan University, China \\ matthiasthurer@workloadcontrol.com \\ ${ }^{4}$ Norwegian University of Science and Technology, Norway \\ daryl.j.powell@ntnu.no \\ ${ }^{5}$ West Virginia University, USA \\ thwuest@mail.wvu.edu
}

\begin{abstract}
Lean Manufacturing and Industry 4.0 are at times portrait as conflicting paradigms. However, we take the stance that they are two sides of the same coin, and should be considered as mutually beneficial. Based on this understanding, this paper is part of a series where we discuss established Lean practices in the emerging Digital Lean Manufacturing World. In this paper, we specifically focus on the issue of "buffer waste", and what that implies within a cyber-physical production system. We discuss the vicious cycle of Mura, Muri, and Muda, and provide observed examples in industry for "buffer waste" from four different, yet interdependent perspectives: (i) physical to physical, (ii) physical to digital, (iii) digital to physical, and (iv) digital to digital. The results of this study confirm that "buffer waste" is indeed an issue that deserves our attention as academics and practitioners in the emerging Digital Lean Manufacturing environment.
\end{abstract}

Keywords: Digital Manufacturing, Smart Manufacturing, Lean Manufacturing, Digital Lean Manufacturing, Digital Lean Enterprise, Cyber-Physical Production Systems, Industry 4.0, Muda, Mura, Muri, Waste, Digital Waste, Obvious Waste, Buffer Waste.

\section{Introduction}

The systematic identification and elimination of waste is one of the main principles of Lean Manufacturing [1] [2] in order to create and deliver value more "efficiently" to the customer. In the Lean lexicon, Muda is the Japanese word for "waste". According to the Toyota principles, three MUs - Muda together with Mura (unevenness) and Muri (overburden) - represent the three biggest enemies of lean production efficiency [2]. While there exists a broad literature on the three $M U s$ in the physical world, research lacks in understanding how Muda, Muri, and Mura influence each other in the context of the evolution of traditional Lean Manufacturing systems, in the Industry 4.0 era [3], towards Digital Lean Manufacturing (DLM) systems. The latter, defined by [4] as a 
"Lean Manufacturing System that builds on data acquisition, data integration, data processing and data visualization capabilities [5] to create different descriptive, predictive and prescriptive analytics applications [6] to detect, fix, predict and prevent unstable process parameters and/or avoid quality issues inside defined tolerance ranges that may lead to any type of waste within the cyber- and physical- worlds". A DLM System involves the generations of two types of Muda (waste) according to its physical or digital plane of manifestation, thus calling for a more holistic and systemic planning of physical and digital waste management [4].

On these premises, this paper discusses the new cyber-physical scope of Muda, Muri, and Mura in the emerging DLM systems, and provide general recommendations for physical and digital waste identification and elimination strategies under a holistic and systemic approach. The proposed recommendations are supported by a conceptual framework built upon a scientific literature review on "waste" meaning and its different types and typologies and are derived from discussion-based interviews with Lean Researchers and Managers, as well as the authors' experiences as Lean Pracademics.

\section{Literature Review}

Traditionally, Muda covers seven distinct types of waste: (i) defects, (ii) overproduction, (iii) waiting, (iv) transportation, (v) inventory, (vi) motion, and (vii) over-processing [2]. Recently, an eighth waste-type emerged: not-utilizing talent [7].

Several extensions of the classical concept of Muda have been presented in the literature. A first relevant distinction about waste-types is provided by [8], from a strategic waste identification and elimination perspective, dividing waste in (i) obvious waste - as any waste that can be reduced or eliminated without creating another form of waste, and (ii) buffer waste - as any waste that cannot be reduced or eliminated without creating another waste. This division helps Lean Managers to strategically plan their waste management actions in order to best achieve (lean) performance targets [8]. Nevertheless, not all obvious wastes can be eliminated. According to [2], there are wastes that are related to non-value-added activities for the customer, but are necessary for the current operational activities; like special controls requested by an independent body in order to issue a certification that a product, process or system meets specific requirements (e.g. ISO standards), therefore, these obvious wastes can only be reduced not eliminated.

Muri is defined as the unreasonable burden of operators or equipment. It refers to any action that relates a tangible-physical or intangible-psychological stress condition. Examples of Muri involving operators are bending to work, lifting heavy weights, or repeating tiring mental and physical actions, while given deadlines that are constantly too short for the workers' individual skill level [9]. Hence, the interconnected nature of most production processes can cause Muri, especially when too many/much Mudas are removed from a specific point in a process (i.e. over-optimization). As a result, Muri can cause $M u d a$, as in the case of a breakdown or defects generated due to the overutilization of machines and/or people, or due to the over-optimization of a process since lean efficiency means a balanced, stable, and standardized process [2] [10]. For instance, the introduction of rigorous standards for the execution of work activities forces the workforce to operate in limiting and alienating conditions that create stress and resistance [11]. 
Finally, Mura identifies the irregular use of a person or a machine. It can be found in any process (or operation) fluctuation, which should be reduced or eliminated in order to avoid the possibility of Muri in any value-adding production resource (e.g. an operator, a machine tool, a robot, a computer, etc.), and therefore, Muda [2]. Indeed, Mura is strongly connected with both Muri and Muda. Consequently, processes' fluctuations are related to their instability, and in turn, create conditions which generate waits and queues. Together with the over-utilization of one or more of the production resources involved at specific times and phases in a process lead to Muda and Muri emerging, and call for the creation of stocks and buffers to overcome such variability in the processes, thus, more Mudas appear.

\section{Muda, Muri \& Mura in a Digital Lean Manufacturing System}

As described before, the three $M U s$ have been traditionally interrelated in the physical world. Moreover, the traditional vicious cycle, where the creation of Mura involves the generation of Muri which, in turn, produces Muda thus creating new Mura, can be replaced by other potential combinations. For example, as depicted in Fig. 1, "inventory" is Muda. The reason for this inventory is variability or Mura [12]. The reason for Mura is typically "overburden" somewhere in the system, i.e. Muri. But the high inventory itself puts even more burden on the systems. This further strains the system and leads to more Mura and, consequently, even more Muda. Breaking this vicious cycle is the main objective of Lean Managers.

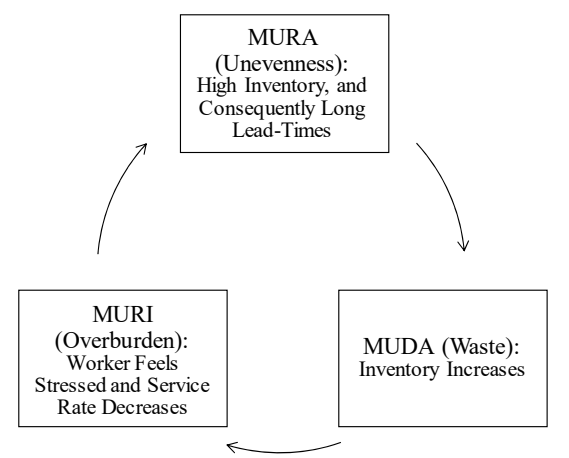

Fig. 1. Mura, Muri, and Muda Vicious Cycle

While breaking this cycle is a challenging task, with the novel cyber-physical nature of production systems [13], Muda, Muri, and Mura have gained a second digital plane of manifestation with also interrelations between their physical and digital nature. This results in at least IV different domains in which waste is created as illustrated in Fig. 2. Note that the vicious cycle depicted in Fig. 1 also exists in the digital plane. Unevenness between information processing requirements and information processing capability, i.e. Mura, leads to large amounts of unused data, i.e. Muda. This, in turn, puts more strain on the system (i.e. Muri) since it negatively effects decision-making [14], which leads to even more Mura and, consequently, Muda. 


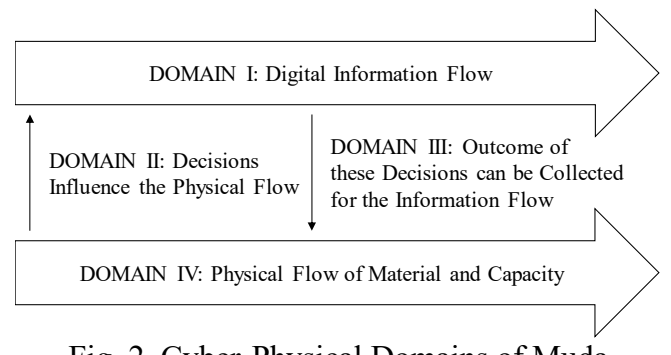

Fig. 2. Cyber-Physical Domains of Muda

As a result, these emerging DLM systems call for a more holistic and systemic planning of physical and digital waste identification and elimination strategies by Digital Lean Managers, always avoiding the creation of another form (type) of waste in one or both of the cyber- and physical- production system worlds. Moreover, Muri and Mura in any of the production resources may result in one or more of the classical seven cases of Muda [2]. Additionally, the eight waste-type of "non-utilizing talent" [7], in the form of non-properly trained operators, in Muri and Mura for such operators due to high-stress levels when aiming to perform standard operations without the proper knowledge and skills, leads in particular in many occasions to one or more of the already mentioned classical seven Mudas in the production line when it comes to aiming for a continuous flow and zero-defects manufacturing system. In general, the interrelation between Mura, Muri, and Muda can be understood as a "vicious cycle" (see Fig. 1).

In the next sub-sections, we discuss the new cyber-physical scope of the three $M U s$ in the emerging DLM systems through a set of non-extensive real examples and provide general recommendations for physical and digital waste identification and elimination strategies under a holistic and systemic approach. In particular, we focus on buffer waste. This is waste that is created by Mura or Muri and can consequently not be reduced without creating another waste.

\subsection{From the Physical World to the Physical World}

According to [15], Muda, Muri, and Mura are connected with each other through a chain of causes and effects in the physical world, where Mura creates Muri and the two of them together create Muda. For example, variations in production volumes force a company to alternate between overloading and underutilizing its production resources, consequently resulting in Muri and Muda (overproduction). This, in turn, leads to downtimes, mistakes, backflows, and waiting times causing other types of Muda. Therefore, Mura and Muri are the root-causes of Muda, creating more non-valued added activities and undercutting previous efforts to eliminate waste [15] (see Fig. 3). 


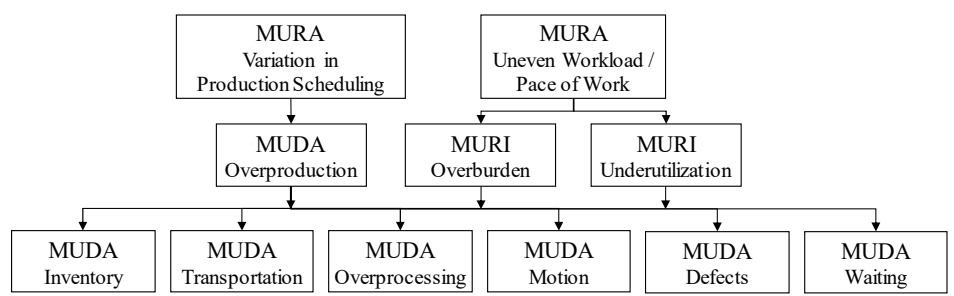

Fig. 3. Interdependencies of Mura, Muri, and Muda [15]

Hence, Digital Lean Managers should always remember that any waste reduction and/or elimination strategy must be based on a "holistic" approach, considering the importance of the whole production system and the interdependencies of its operations and resources in order to not create more waste when trying to remove it.

\subsection{From the Physical World to the Digital World... to the Physical World}

The Internet of Industrial Things (IIoT) offers tremendous new opportunities for capturing data from the physical world in order to create digital records to support a smart production planning and control. Through "smart" interventions, by applying advanced modelling, simulation, and (big) data analytics techniques [16-18], it is now possible for Digital Lean Managers to analyse data from multiple sources and visualize it in real-time and interactive-matter in digital dashboards in order to make better decisions supported by hard-data and various scenarios-testing. These aims lead to Kaizen (improvement) actions with higher levels of success. Nevertheless, in the previous scenario described poor data quality, acquired through damaged or tampered sensors may lead to digital waste, in case it is not detected on-time and at the level of the enterprise information systems, and even worse to physical waste, in case decisions were made and actions were taken based on incomplete, no longer valid, inconsistent, and/or not accurate data. Furthermore, digital obvious waste identification in the form of poor data quality represents one of today's biggest challenges in DLM systems, urging Digital Lean Managers to implement: Total Data Quality Management (TDQM) practices [19-21].

\subsection{From the Digital World to the Physical World}

There is no question that advanced modelling, simulation, and (big) data analytics tools [16-18] may offer great optimization capabilities at the production line. Nevertheless, such analytical efforts should not create waiting times and queues for the production resources due to what can be described as "paralysis by analysis". The use of digital/ smart manufacturing technologies [22] [23] supports operators in simple and repetitive tasks (i.e. routines), and helps them to reduce quality defects as the technology is not exposed to the risk of "human error". Thus, contributing to "predictable" and "stable" processes outputs. For instance, the adoption of digital poke-yokes avoids the generation of errors during production. It allows to record the actions taken by each operator and produce real-time tutorials to guide users in the optimized use of their tools (e.g. augmented reality assistance systems), speeding-up their operations, and minimizing future errors and reworks [23]. This implies a potential reduction of fluctuations that 
are generated when different production practices are adopted by workers characterized by distinctive learning approaches. Another example is the use of exoskeletons, which allow reducing the physical overloads in the case of heavy and repetitive tasks, thus avoiding loss of productivity and quality [23].

Introducing digital/smart manufacturing technologies [22] [23] in a production system where processes are not under control, it amplifies the risk for additional physical Muri and Muda. For example, the use of robots/co-bots supports operators in repetitive tasks and helps them to reduce quality defects. However, if each production phase is not well balanced, the speed improvement achieved in robotized areas can involve the creation of bottlenecks both downstream and upstream of the production system that in turn cause generation of stocks and waits.

Finally, high-levels of automation can cause stress at the organizational level, and push operators to reduce their effort, interest, and commitment towards their work with a consequent risk of creating new forms of Muda in the production operations.

In these cases, the ability of the management to plan and communicate properly the introduction of automation will be very important in order to avoid unnecessary stress into the organization. Moreover, Digital Lean Managers should avoid over-engineering their cyber-physical production systems, and adding unneeded "complexity" to their operations, which may increase the potential of catastrophic, but also incremental, failure of the system [4]. Some recommendations to avoid this situation have been provided by [24] and [25] based on various design principles for Industry 4.0 solutions, which advocate for decentralised structures and for small and simple-to-integrate modules (i.e. plug-and-play) in order to better manage their complexity as well as the complexity of the overall system when being adopted.

\subsection{From the Digital World to the Digital World}

The digitalization of paper-based information flows as well as capturing data from the physical world thanks to the IIoT, offer new opportunities to envision the paperless and proactive sensing factory [26]. This vision aims to provide availability and access of everything online, readily available for advanced data analytics and information "push" technologies (e.g. real-time and interactive digital dashboards, artificial intelligencebased reporting tools, wearable Andon systems). Thus, digital information flows, digital visual controls and human-machine interfaces in these new data-rich manufacturing environments called: "smart factories", should be now more than ever designed in a way that they avoid cognitive Muri [27] for the operators due to information saturation. Some cognitive Muri cases that should be avoided in DLM environments are: (i) not properly designed augmented reality (digital) assistance systems that are overwhelming operators with information in their direct view, (ii) over-engineered human-machine interfaces (i.e. control panels) making it hard for the operators to control a machine tool, a robot, or a computer system, (iii) complex dashboards (i.e. data visualizations) making it difficult for the operators to interpret the information provided, (iv) abuse of Andon systems to the point that operators may decide to ignore the alarms (i.e. alarm fatigue), and (v) irrelevant reports for supporting decision-making. Hence, Digital Lean Managers should promote and adopt "cognitive ergonomics" best practices [28] to avoid Muri. 


\section{Conclusions}

In the emerging Digital Lean Manufacturing World, we have to rethink the established concept of the seven (or eight) wastes. We have to recognize, that both physical and digital waste exist and have to be addressed individually while keeping a holistic perspective. While digital waste currently appears to be less of a problem, seen computer power is typically less costly, there are two issues that need to be considered. First, computer power is, in fact, limited and many optimisation problems cannot be solved. There are also problems with storage and retrieval of large unnecessary data, something already recognized by [2]. Second, managers are unlikely to give control to a machine. The human will remain a central aspect of any management system. As a consequence, the main task in "digital management" is the reduction of data to the essential information to allow a human user to make an informed decision. But this is itself just Muda elimination, being any data that does not contribute to the informed decision is Muda. In this paper, we specifically focussed on the "buffer waste". Buffer waste in a DLM system is created by Mura or Muri, and can consequently not be reduced or eliminated without creating another waste.

Moreover, we have discussed the issue of buffer waste and its impact on DLM systems taking four different, interdependent perspectives: (i) from the physical world to the physical world; (ii) from the physical world to the digital world, and back to the physical world; (iii) from the digital world to the physical world; as well as (iv) from the digital world to the digital world. In doing so, we recognize that there is a wide range of Muda that emerges when digital/smart technologies [21] [22] are introduced in a manufacturing system. For example, introducing (co-)robots in a manufacturing system to support operators at the assembly line does address Muda and Muri, however, can negatively impact process fluctuations: Mura. This dilemma has been termed: Mura, Muri, and Muda vicious cycle.

This paper is a first attempt to discuss the issue of buffer waste in a DLM system from a holistic perspective. The results confirm that this is indeed a problem deserving of our attention as researchers with a strong impact on manufacturing practice. Future work needs to focus on defining the interdependencies between the different Mudas, ideally in detailed case studies as a basis for instruments and methods addressing the effective and efficient design of DLM practices.

\section{References}

1. Womack, J.P., Jones, D.T.: Lean Thinking: Banish Waste and Create Wealth in your Corporation. New York, NY: Simon \& Schuster (1996)

2. Ohno, T.: Toyota Production System: Beyond Large Scale Production. Productivity Press, Portland, Oregon (1988)

3. Mora, E., Gaiardelli, P., Resta, B., Powell, D.: Exploiting Lean Benefits Through Smart Manufacturing: A Comprehensive Perspective. Part I, IFIP AICT 513:127-134 (2017)

4. Romero, D., Gaiardelli, P., Powell, D., Wuest, T., Thürer, M.: Digital Lean Cyber-Physical Production Systems: The Emergence of Digital Lean Manufacturing and the Significance of Digital Waste. Part I, IFIP AICT 535:11-20 (2018)

5. Kusiak, A.: Smart Manufacturing Must Embrace Big Data. Nature, 544(7648):23-25 (2017)

6. Wuest, T., Weimer, D., Irgens, C., Thoben, K.-L.: Machine Learning in Manufacturing: Advances, Challenges, and Applications. J. Production \& Mfg. Research, 4(1):23-45 (2016) 
7. Liker, J.K.: The Toyota Way: 14 Management Principles from the World's Greatest Manufacturer. McGraw-Hill, New York (2004)

8. Thürer, M., Tomašević, I., Stevenson, M.: On the Meaning of 'Waste': Review and Definition, Production Planning \& Control, 28(3):244-255 (2017)

9. Arezes, P., Carvalho, D., Carvalho, A.A.: Threats and Opportunities for Workplace Ergonomics in Lean Environments. 7th International Annual EurOMA Conference (2010)

10. Hampson, I.: Lean Production and the Toyota Production System Or, the Case of the Forgotten Production Concepts. Economic and Industrial Democracy, 20:369-391 (1999)

11. De Treville, S., Antonakis, J.: Could Lean Production Job Design be Intrinsically Motivating? Contextual, Configurational, and Levels-of-Analysis Issues. J. of Operations Management, 24(2):99-123 (2006)

12. Hopp, W.J., Spearman, M.L.: Factory Physics: Foundations of Manufacturing Management, McGraw-Hill, 2nd Edition (2001)

13. Powell, D., Romero, D., Gaiardelli, P., Cimini, C., Cavalieri, S.: Towards Digital Lean Cyber-Physical Production Systems: Industry 4.0 Technologies as Enablers of Leaner Production. Part II, IFIP AICT 535:353-362 (2018)

14. Tushman, M.L., Nadler, D.A.: Information Processing as an Integrating Concept in Organizational Design. Academy of Management Review, 3(3):613-624 (1978)

15. Pieńkowski, M.: Waste Measurement Techniques for Lean Companies. Int'l. J. of Lean Thinking, 5(1):9-24 (2014)

16. Shao, G., Shin, S.-J., Jain, S.: Data Analytics using Simulation for Smart Manufacturing. Proceedings of the Winter Simulation Conference (2014)

17. Tsironis, L., Bilalis, N., Moustakis, V.: Using Machine Learning to Support Quality Management: Framework and Experimental Investigation. The TQM Magazine, 17(3):237248 (2005)

18. Venkata, R.R.: Advanced Modeling and Optimization of Manufacturing Processes International Research and Development. Springer-Verlag London (2011)

19. Wang, R.Y.: A Product Perspective on Total Data Quality Management. Communications of the ACM, 41(2):58-65 (1998)

20. Perez-Castillo, R., et al.: Data Quality Best Practices in IoT Environments. IEEE 11th Int'l. Conf. on the Quality of Information and Communications Technology (2018)

21. Romero, D., Gaiardelli, P., Powell, D., Wuest, T., Thürer, M.: Total Quality Management and Quality Circles in an Emerging Digital Lean Manufacturing World. APMS (2019)

22. Sameer, M., Muztoba, K., Romero, D., Wuest, T.: Smart Manufacturing: Characteristics, Technologies and Enabling Factors. J. of Engineering Manufacture (2017)

23. Romero, D., Stahre, J., Wuest, T., Noran, O., Bernus, P., Fast-Berglund, Å., Gorecky, D.: Towards an Operator 4.0 Typology: A Human-Centric Perspective on the Fourth Industrial Revolution Technologies. Int'l. Conf. on Computers \& Industrial Engineering (CIE46) Proceedings, Tianjin/China, pp. 1-11 (2016)

24. Hermann, M., Pentek, T., Otto, B.: Design Principles for Industrie 4.0 Scenarios. $49^{\text {th }}$ Hawaii Int'l. Conf. on System Sciences, pp. 3928-3937, IEEE (2016)

25. Lee, J., Bagheri, B., Kao, H.A.: Recent Advances and Trends of Cyber-Physical Systems and Big Data Analytics in Industrial informatics. IEEE Int'1. Conf. on Industrial Informatics (2014)

26. Magoutas, B., et al.: Anticipation-driven Architecture for Proactive Enterprise Decision Making. 26th Int'l. Conf. on Advanced Information Systems Engineering, Vol. 1164, pp. 12-128 (2014)

27. Kumar, N., Kumar, J.: Efficiency 4.0 for Industry 4.0. Human Technology, 15(1):55-78 (2019)

28. Long, J.: Cognitive Ergonomics - Past, Present, Future: 10 Lessons Learned (10 Lessons Remaining). Human Factors \& Ergonomics Society Annual Meeting, 44(6):557-560 (2000) 